\title{
Frequency of thyroid carcinoma and thyroid autoimmunity in first- degree relatives of patients with papillary thyroid carcinoma - A single center experience
}

\author{
Frequência de carcinoma de tireoide e autoimunidade \\ tireoidiana em parentes de primeiro grau de portadores de \\ carcinoma de tireoide - Experiência de um único centro
}

Elaine Maria dos Santos Gomes', Fernanda Vaisman', Ana Paula Vidal'2, Rossana Corbo ${ }^{3}$, Manuel Domingos Gonçalves da Cruz ${ }^{4}$,

Patricia de Fatima dos Santos Teixeira ${ }^{3}$, Alexandru Buescu ${ }^{3}$, Mario Vaisman ${ }^{3}$

1 Post graduate fellows Program in Endocrinology, Medical School, Universidade Federal do Rio de Janeiro (UFRJ), Rio de Janeiro, RJ, Brazil ${ }^{2}$ Anatomical Pathology Service, HUCFF, UFRJ, Rio de Janeiro, RJ, Brazil ${ }^{3}$ Endocrinology Service, Hospital Universitario Clementino Fraga Filho (HUCFF), UFRJ, Rio de Janeiro, RJ, Brazil

${ }^{4}$ General Surgery Service, HUCFF, UFRJ, Rio de Janeiro, RJ, Brazil
Correspondence to: Fernanda Vaisman Rua General Venancio Flores $368 / 302$

22441-090 - Rio de Janeiro, RJ, Brazil

fevaisman@globo.com

Received on Dec/20/2010 Accepted on May/13/2011

\begin{abstract}
Objective: To evaluate the frequency of thyroid cancer and thyroid dysfunction in first-degree relatives of thyroid cancer patients, and to determine if there is a difference between familial and sporadic thyroid cancer. Subjects and methods: Fifteen first-degree relatives of seven families with at least two family members with thyroid cancer (TC) were compared with 128 first-degree relatives of 45 families with only one family member affected. Laboratory and ultrasound evaluation, fine-needle aspiration biopsy and thyroid surgery were used as normally done in clinical practice. Results: Thyroid dysfunction was similar between the two groups. The frequency of TC and autoimmunity in the group that had two relatives with known thyroid cancer was higher, compared with the families that had sporadic thyroid cancer among their family members $(40 \%$ vs. $2 \%, p=0.0001)$. Conclusion: Frequency of TC increases when more than one member of the family is affected. These findings suggest that these relatives should be screened more frequently than individuals in families in which only one case ofTC is observed. Arq Bras Endocrinol Metab. 2011;55(5):326-30
\end{abstract}

Keywords

Nonmedullary familial thyroid cancer; thyroid dysfunction; thyroid nodules

\section{RESUMO}

Objetivo: Avaliar a frequência de carcinoma de tireoide e disfunção tireoidiana em parentes de pacientes com câncer da tireoide e determinar se há diferença entre aqueles com mais de um familiar acometido e os casos esporádicos. Sujeïtos e métodos: Quinze familiares de sete famílias com dois membros sabidamente acometidos foram submetidos à avaliação ultrassonográfica e laboratorial. Cento e vinte e oito familiares de pacientes com carcinoma de tireoide, porém sem outros casos na família, foram utilizados como grupo comparador. Resultados: Em relação à disfunção tireoidiana, não houve diferença entre os grupos. A frequência de carcinoma da tireoide e autoimunidade foi maior nos parentes que tinham dois membros da família afetados $(40 \%$ vs. $2 \%, p=0.0001)$. A apresentação clínica foi semelhante nos dois grupos. Conclusão: Devido à maior frequência de carcinoma de tireoide em parentes que possuem mais de um familiar afetado, o rastreamento desses indivíduos talvez deva ser mais intenso do que nos casos em que há apenas um caso na família. Arq Bras Endocrinol Metab. 2011;55(5):326-30

Descritores

Carcinoma familiar não medular da tireoide; disfunção tireoidiana; nódulos tireoidianos 


\section{INTRODUCTION}

$\mathrm{T}$ hyroid cancer accounts for only $1 \%$ of all malignant tumors, but it is still the most common endocrine malignancy, with a current estimated incidence of 33,500 new cases per year in the United States (1). Though most cases of follicular-derived neoplasms are sporadic, familial forms have been reported, comprising approximately $5 \%$ of cases (2). Familial nonmedullary thyroid cancer (FNMTC) is defined by the diagnosis of two or more first-degree relatives with follicular thyroid cancer, without another familial syndrome $(3,4)$. Currently, it is estimated that from $3.5 \%$ to $6.2 \%$ of the cases of nonmedullary thyroid carcinomas are family cancers (5-10). Most of them are papillary thyroid carcinomas, which are observed in more than $90 \%$ of the cases (11-13).

Genetic inheritance of FNMTC remains unknown, but it is believed to be an autosomal dominant condition with incomplete penetrance and variable expressivity. Genetic analyses of large FNMTC kindreds is the first step in the identification of putative susceptibility genes $(14,15)$. However, there is no genetic test that correlates with phenotype that could be used for therapeutic and follow-up decisions. In this scenario, it is important that practitioners are aware of the incidence of thyroid cancer cases, and of how to follow up relatives of these patients.

There are still some controversial issues regarding clinical presentation and overall disease-free survival in FNMTC. Several studies found patients with FNMTC to have increased risk of multifocal disease, local invasion, and lymph node metastases, leading to higher recurrence rates, and decreased disease-free survival $(12,13)$. However, other studies did not find FNMTC to be more aggressive than the sporadic disease $(16,17)$.

The use of cervical ultrasound examination for screening asymptomatic patients is increasing. Ultrasound enables earlier detection of occult nonpalpable thyroid cancers in asymptomatic relatives of patients with FNMTC (9). Uchino and cols. (9) reported a prevalence of $52 \%(77 / 149)$ in thyroid nodules detected by neck ultrasound screening performed on asymptomatic relatives of patients with FNMTC. Given the prevalence of thyroid cancer, clustering of sporadic thyroid cancer in one family may not be rare. It has been estimated that $62 \%-69 \%$ of families with two affected relatives are sporadic occurrences, whereas the chance of a sporadic case in families that have three or more affected members is less than 6\% (17). Additionally, nonmalignant thyroid disease is frequently seen in patients with FNMTC (36\%-57\%), including follicular adenomas, Hashimoto's thyroiditis, multinodular goiter, hyperthyroidism, and hypothyroidism $(5,8)$.

The aim of this study was to determine the frequency of thyroid cancer, adenomas and thyroid dysfunction in first-degree relatives of FNMTC patients and in sporadic thyroid cancer cases in a tertiary-care center.

\section{SUBJECTS AND METHODS}

From all the patients seen at the Endocrine Service for thyroid cancer, there were seven families with at least two members affected by thyroid cancer. First-degree relatives from those 15 patients with papillary thyroid cancer (PTC) were invited to participate in this study (Group 1). They were the third member of these families to be screened. As a comparison group, first-degree relatives of 45 families with only one member affected by PTC were evaluated (Group 2). All the patients were followed up as outpatients in the Endocrinology Service of Hospital Universitario Clementino Fraga Filho, Universidade Federal do Rio de Janeiro (HUCFF-UFRJ). The average number of family members in each group was 2.75 . However, the average living first-degree relatives who could potentially be part of the study was 4.59 . The main reasons for not participating in the study were the distance between their homes and the HUCFF (many lived in other cities or States), and incompatibility between scheduled appointments and exams with the work routine of the subject.

The inclusion criteria were age between 15 and 80 years, and at least one family carrier of papillary thyroid carcinoma. All first-degree relatives were invited to participate in the study.

The exclusion criteria were presence of family syndromes associated with nonmedullary thyroid carcinoma (familial adenomatous polyposis, Cowden's disease, Werner's syndrome, Carney's complex type 1 etc.).

This study was approved by the Ethics Committee of the hospital.

\section{Laboratory evaluation}

Blood samples for laboratory analysis were collected to assess thyroid dysfunction by measuring TSH and free T4 (FT4), and to evaluate autoimmunity the TPO antibody (ATPO). TSH was determined by DPC (Diagnostic Products Corporation) Immulite ${ }^{\circledR} 2000$ chemiluminescence TSH third-generation kit. Reference values (VR), 0.4-4.0 mUI/L; sensitivity, $0.002 \mathrm{mUI} / \mathrm{L}$; intra-assay coefficient of variation (CV), 3.8-12.5\%; and inter-assay CV, 4.6-12.5\%. Free T4 (FT4) was measured 
by means of DPC Immulite ${ }^{\circledR} 2000$ chemiluminescence enzyme-linked immunosorbent assay kit. VR, 0.8-1.9 $\mathrm{ng} / \mathrm{dL}$; sensitivity, $0.15 \mathrm{ng} / \mathrm{dL}$; intra-assay $\mathrm{CV}, 4.4 \%$ 7.5\%; and inter-assay CV, 4.8\%-9.0\%. ATPO analysis was carried out using DPC Immulite ${ }^{\circledR} 2000$ kit. Negative results were equal to or less than $35 \mathrm{IU} / \mathrm{mL}$; intra-assay CV ,4.3\%-5.6\%, and inter-assay CV, 7.8\%-10.5\%.

\section{Thyroid ultrasound examination}

In the first evaluation, subjects underwent thyroid ultrasound examination for morphological evaluation of the thyroid gland, using a SIEMENS, MCMDOIAA ultrasound machine with linear transducer DTMF $11 \mathrm{MHz}$. All ultrasound examinations were performed by the same radiologist of the Radiology Service of HUCFF.

For further evaluation, patients who showed a nodule larger than $1 \mathrm{~cm}$ and smaller nodules with at least three features suggestive of malignancy that had not been studied previously, or that showed changes over time, underwent fine needle aspiration biopsy (FNA). All cytological examinations were read by the same pathologist, who did not have any information on the patient's history. Suspicious features were: hypoechogenicity, microcalcifications, irregular margins, increased blood flow in Doppler evaluation, increased antero-posterior diameter in relation to transverse diameter $(18,19)$, and especially regional lymphadenopathy.

\section{Thyroid surgeries}

Surgery was indicated during the study based on clinical, laboratory and cytological findings. Patients with cytological findings indicative of malignancy and indeterminate pattern were referred for surgery.

\section{Statistical analysis}

Analysis was performed using SPSS software (Version 18.0.1: SPSS Inc, Chicago, IL). Comparison of categories was based on Chi-Square and Fisher's exact test. Data of continuous variables were expressed as medians, minimum and maximum values. Mann-Whitney's non-parametric test was use to compare numeric variables between the groups. Statistical significance was set at $5 \%$.

\section{RESULTS}

From the 143 family members who agreed to participate in the study, $15(10.5 \%)$ had at least two relatives with papillary thyroid cancer, and $128(89.5 \%)$ had only one. About two relatives per "index-case" were evaluated, and most patients were females, in both groups. Median FT4 and TSH, at the time of PTC diagnosis, were similar in both groups, but autoimmunity was more frequent in individuals who had two relatives with thyroid cancer $(26.6 \%$ vs. $5.4 \%, \mathrm{p}=0.016$; Table 1$)$.

Frequency of ultrasound abnormalities, including cysts and nodules, was similar among the relatives in the two groups. It is important to mention that four individuals from Group 1 had their ultrasound examination and guided fine needle aspiration biopsy performed outside of our Institution, and their cytology results were reviewed at the HUCFF by the same pathologist who analyzed the other cases. However, from the patients who underwent fine needle aspiration biopsy (7 in the relatives of Group 1, and 17 in the relatives of Group 2), malignant or indeterminate cytology was much more frequent $(46.6 \% v s .4 .6 \%)$ in the group that had two relatives with known thyroid cancer. As expected, histological examination after surgery confirmed this difference between the two groups $(40 \%$ vs. $2 \%$, $\mathrm{p}=0.0001$ ). Interestingly, all the relatives from Group 1 patients who showed indeterminate cytology results, turned out to have thyroid cancer after surgery. This finding, however, was not observed in Group 2 ( $\mathrm{p}=0.09$ ).

Clinical presentation of the newly diagnosed thyroid cancers was similar in both groups regarding size, histology and initial staging. Characteristics of relatives of FNMTC patients (Group 1) are shown in Table 2.

Table 1. Characteristics of the entire cohort

\begin{tabular}{lccc}
\hline & $\begin{array}{c}\text { Group 1 } \\
(\mathbf{n = 1 5 )}\end{array}$ & $\begin{array}{c}\text { Group 2 } \\
(\mathbf{n = 1 2 8})\end{array}$ & p-value \\
\hline Family members/patient & 2.1 & 2.3 & 0.850 \\
Gender (female) & $60 \%$ & $67.9 \%$ & 0.562 \\
Age & $49(22-60)$ & $43.5(15-75)$ & 0.913 \\
Thyroid function tests & & & \\
$\quad$ TSH & $1.45(0.01-39.5)$ & $1.85(0.06-10.6)$ & 0.157 \\
FT4 & $1.45(1.28-2.24)$ & $1.30(0.71-2.95)$ & 0.890 \\
ATP0 + & $26.6 \%$ & $5.4 \%$ & $\mathbf{0 . 0 1 6}$ \\
US & & & \\
$\quad$ Normal & $4 / 11(36.4 \%)$ & $55 / 118(46.6 \%)$ & 0.75 \\
$\quad$ Abnormal & $7 / 11(63.6 \%)$ & $63 / 118(53.4 \%)$ & \\
FNA & & & \\
$\quad$ Malignant & $26.6 \%$ & $2.3 \%$ & $\mathbf{0 . 0 0 3}$ \\
Indeterminate & $20 \%$ & $2.3 \%$ & $\mathbf{0 . 0 1 9}$ \\
Final diagnosis & & & \\
$\quad$ Thyroid cancer & $40 \%$ & $2 \%$ & $\mathbf{0 . 0 0 0 1}$ \\
\hline
\end{tabular}


Table 2. Families with known FNMTC (two known cases in the family)

\begin{tabular}{|c|c|c|c|c|c|c|c|}
\hline Families with FNMTC & 1 & 2 & 3 & 4 & 5 & 6 & 7 \\
\hline Number of relatives in the study & 3 & 1 & 1 & 2 & 3 & 4 & 1 \\
\hline Relatives with abnormal US results & 1 & 1 & 0 & 2 & 1 & 1 & 1 \\
\hline Relatives with abnormal thyroid function test results & $\begin{array}{c}1 \\
\text { (subclinical } \\
\text { Hyper) }\end{array}$ & 0 & 0 & 0 & $\begin{array}{c}1 \\
\text { (subclinical } \\
\text { Hypo) }\end{array}$ & & $\begin{array}{c}1 \\
\text { (subclinica } \\
\text { Hyper) }\end{array}$ \\
\hline ATPO + & 1 & 0 & 0 & 2 & 0 & 1 & 0 \\
\hline Indication for FNA & 1 & 1 & 0 & 2 & 1 & 1 & 1 \\
\hline Relatives with confirmed thyroid cancer & 1 & 1 & 0 & 1 & 1 & 1 & 1 \\
\hline Relationship to index case & Daughter & Son & - & Mother & Sister & Mother & Sister \\
\hline Histology & PTC & PTC & - & PTC & PTC & PTC & PTC \\
\hline Age of new cases & 49 & 40 & - & 48 & 46 & 47 & 39 \\
\hline AJCC stage & 1 & 1 & - & 2 & 1 & 1 & 1 \\
\hline
\end{tabular}

AJCC: American Joint Committee on Cancer.

As expected, the majority of the families with two members with known thyroid cancer had at least another case diagnosed during the study ( 6 out of 7 families had a third member with thyroid cancer, $85.7 \%)$. Regarding thyroid function, two families had one person with subclinical hypothyroidism, and one with subclinical hyperthyroidism. Relatives were diagnosed between the forth and fifth decades and $85.7 \%$ ( 6 relatives) were stage I. Only one relative was stage 2 because of a 2.3 $\mathrm{cm}$ tumor. None of them had lymph node metastases.

\section{DISCUSSION}

In this study, the frequency of thyroid structural and functional alterations in first-degree relatives of FNMTC patients was analyzed considering either benign or malignant findings. Among the 7 families with FNMTC followed up in the Endocrine Service of the HUCFF-UFRJ, the frequency of thyroid cancer was $46.6 \%$, as opposed to the relatives who had only one affected family member, and were followed up in the same institution. Other studies have shown that when there are two people in a family with NMTC, the risk of familial syndrome is between $31 \%$ and $53 \%$, but when there are three or more subjects affected with NMTC, the risk of a familial syndrome exceeds $95 \%(20,21)$.

Based on the literature and regarding thyroid dysfunction and benign lesions, expected frequency would be $36 \%-57 \%$, including follicular adenomas, Hashimoto's thyroiditis, multinodular goiter, hyperthyroidism, and hypothyroidism $(5,8)$. However, the frequency of benign lesion we observed was lower than that. This might be due to the relatively small number of relatives analyzed per patient. On the other hand, Hashimoto's thyroiditis was more frequent in the group of relatives of FNMTC patients. Other authors reported that FNMTC patients showed nine times more common association with lymphocytic thyroiditis (22).

As shown in this study, the majority of the family members evaluated did not have thyroid cancer. Because of that, it is still unclear how these individuals should be followed up. Charkes and cols., found that the probability of two cases of sporadic differentiated thyroid cancer in a 9-member first-degree family was about $40 \%$, and that a significant majority of two-hit families were composed of sporadic cases only. They recommended that clinical and genetic investigations of FNMTC should focus on families of three or more affected members.

Even though there were a small numbers of families with FNMTC, newly-diagnosed cases did not have a more aggressive presentation, and in this study it was not possible to determine if they occurred earlier, because these new cases were from different generations. However, some studies demonstrated that patients with familial papillary thyroid carcinoma display an imbalance of the telomere-telomerase complex in peripheral blood, characterized by short telomeres, and hTERT gene amplification and expression. These features may be implicated in the inherited predisposition to develop familial papillary thyroid carcinoma, and decreased telomere length may play a role in age-related genetic instability, so that cancer appears in early ages $(23,24)$.

This study has important limitations. In both groups, not all the first-degree relatives were evaluated. Thus, some cases might have been missed. Furthermore, some 
cases of microcarcinoma might also have been missed due to the fact that not all the individuals underwent surgery because of ethical considerations. In addition, the number of first-degree relatives of families with two or more known patients with PTC (Group l) is nearly 9 times less than the number of first-degree relatives of families with only one known patient with PTC (Group 2), which might have affected statistical analysis.

This study shows the importance of FNMTC as a distinct clinical entity, but follow-up of first-degree relatives of these patients is still controversial. Recommendations are that all members of affected families, even asymptomatic ones, should to be assessed accordingly. Because genetic testing for FNMTC is unavailable, it is imperative that these individuals undergo careful history analysis and thorough physical examination. This should be followed by ultrasound examination of the thyroid gland and cervical lymph nodes, and fine needle aspiration biopsy, when thyroid nodules or suspicious nodules are identified, followed by appropriate surgical treatment. However, this conduct is based on single center or opinion of experts. Because of that, it is important to know the frequency of the disorder in different population, data that might help us understand familial penetrance and determine the ideal follow-up regimen for these individuals.

Disclosure: no potential conflict of interest relevant to this article was reported.

\section{REFERENCES}

1. Nose V. Familial non-medullary thyroid carcinoma: an update. Endocr Pathol. 2008;19:226-40.

2. Kebebew E. Hereditary non-medullary thyroid cancer. World $\mathrm{J}$ Surg. 2008;32:678-82.

3. Grossman RF, Tu SH, Duh QY, Siperstein AE, Novosolov F, Clark $\mathrm{OH}$. Familial nonmedullary thyroid cancer. An emerging entity that warrants aggressive treatment. Arch Surg. 1995;130:892-7 discussion 898-9.

4. Triponez F, Wong M, Sturgeon C, Caron N, Ginzinger DG, Segal $\mathrm{MR}$, et al. Does familial nonmedullary thyroid cancer adversely affect survival? World J Surg. 2006;30:787-93.

5. Pal T, Vogl FD, Chappuis PO, Tsang R, Brierley J, Renard H, et al. Increased risk for nonmedullary thyroid cancer in the first degree relatives of prevalent cases of nonmedullary thyroid cancer: a hospital-based study. J Clin Endocrinol Metab. 2001;86:5307-12.
6. Fischer DK, Groves MD, Thomas SJ Jr, Johnson PC Jr. Papillary carcinoma of the thyroid: additional evidence in support of a familial component. Cancer Invest. 1989;7:323-5.

7. Stoffer SS, Van Dyke DL, Bach JV, SzpunarW, Weiss L. Familial papillary carcinoma of the thyroid. Am J Med Genet. 1986;25:775-82.

8. Grossman RF, Tu SH, Duh QY, Siperstein AE, Novosolov F, Clark $\mathrm{OH}$. Familial nonmedullary thyroid cancer: an emerging entity that warrants aggressive treatment. Arch Surg. 1995;130:892-9.

9. Uchino S, Noguchi S, Kawamoto H, Yamashita H, Watanabe S, Shuto $\mathrm{S}$. Familial nonmedullary thyroid carcinoma characterized by multifocality and a high recurrence rate in a large study population. Word J Surg. 2002;26:897-902.

10. Kwok CG, Mc Dougall IR. Familial differentiated carcinoma of the thyroid: report of five pairs of sibilins. Thyroid. 1955;5;395-7.

11. Alsanea $\mathrm{O}, \mathrm{Clark} \mathrm{OH}$. Familial thyroid cancer. Curr Opin Oncol. 2001;13:44-51.

12. Sturgeon C, Clark O. Familial nonmedullary thyroid cancer. Thyroid. 2005;15:588-93.

13. Sippel SR, Caron RN, Clark OH. An evidence-based approach to familial nonmedullary thyroid cancer:screening, clinical management, and follow-up. Word J Surg. 2007;31:924-33.

14. Bakhsh A, Kirov G, Gregory GW, Williams ED, Ludgate M. A new form of familial multi-nodular goitre with progression to differentiated thyroid cancer. Endocr Relat Cancer. 2006;13:475-83.

15. McKay JD, Lesueur F, Jonard L, Pastore A, Williamson J, Hoffman $L$, et al. Localization of a susceptibility gene for familial nonmedullary thyroid carcinoma to chromosome 2q21. Am J Hum Genet. 2001;69:440-6.

16. ItoY, Kakudo K, Hirokawa M, Fukushima M, YabutaT,Tomoda C, et al. Biological behavior and prognosis of familial papillary thyroid carcinoma. Surgery. 2009;145:100-5.

17. Maxwell EL, Hall FT, Freeman JL. Familial non-medullary thyroid cancer: a matched-case control study. Laryngoscope. 2004;114:2182-6.

18. Charkes ND. On the prevalence of familial nonmedullary thyroid cancer in multiply affected kindreds. Thyroid. 200616:181-6.

19. Peccin S, de Castsro JA, Furlanetto TW, Furtado AP, Brasil BA, Czepielewski MA. Ultrasonography: is it useful in the diagnosis of cancer in thyroid nodules? J Endocrinol Invest. 2002;25:39-43.

20. Tomimori EK, Bisi H, Medeiros-Neto G, Camargo RY. [Ultrasonographic evaluation of thyroid nodules: comparison with cytologic and histologic diagnosis]. Arq Bras Endocrinol Metab. 2004;48:105-13.

21. Charkes ND. On the prevalence of familial nonmedullary thyroid cancer in multiply affected kindreds. Thyroid. 2006;16:181-6.

22. Charkes ND. On the prevalence of familial nonmedullary thyroid cancer. Thyroid. 1998;8:857-8.

23. Mosso L, Velasco S, Salazar I, Solar A, González H, Cardona B, et al. Clinical features of 17 patients with familial non medullary thyroid carcinoma Rev Med Chil. 2007;135(6):718-24.

24. Capezzone M, Cantara S, Marchisotta S, Filetti S, De Santi MM, Rossi B, et al. Short telomeres, telomerase reverse transcriptase gene amplification, and increased telomerase activity in the blood of familial papillary thyroid cancer patients. J Clin Endocrinol Metab. 2008;93(10):3950-7. Epub 2008 Jul 29 